\title{
Stentless aortic valve replacement in the young patient: long-term results
}

\author{
Torsten Christ, ${ }^{*}$ Herko Grubitzsch, Benjamin Claus and Wolfgang Konertz
}

\begin{abstract}
Background: Stentless aortic valve replacement (SAVR) became a common surgical procedure to treat aortic valve disease, as it offers larger orifice area and improved hemodynamics. The aim of our single-centre retrospective study was to assess long term results of first generation stentless aortic valves in young patients, where mechanical prostheses are considered first line therapy.

Methods: From 1993 to 2001, 188 (149 male and 39 female) patients ( $\leq 60$ years) underwent SAVR. Indications were in $63.3 \%$ stenosis or mixed lesions and in $36.7 \%$ isolated regurgitation. Mean age of patients at surgery was $53.1 \pm 7.1$ years. Associated procedures were performed in 60 patients (31.9\%). Follow-up data were acquired through telephone interviews. Follow-up was $90.4 \%$ complete at a mean of $8.8 \pm 4.7$ years. Total follow-up was 1657.6 patient-years with a maximum of 17 years.

Results: Overall hospital mortality was 3.2\% (2.5\% for isolated SAVR). Overall actuarial survival-rate at 10/15 years and freedom from reoperation at 10/14 years were $73.0 \% \pm 3.5 \% / 55.8 \% \pm 5.4 \%$ and $81.0 \% \pm 3.4 \% / 58.0 \% \pm 7.5 \%$, respectively. For isolated SAVR, actuarial survival at 10/15 years and freedom from reoperation at 10/14 years were $70.1 \% \pm 4.4 \% / 64.1 \% \pm 4.8 \%$ and $83.1 \% \pm 4.0 \% / 52.9 \% \pm 9.0 \%$, respectively. Reoperation was performed in 42 patients (22.3\%) due to structural valve deterioration and endocarditis. Age ( $\leq 50$ years) and associated procedures did not significantly lower survival and freedom from reoperation, however, small prosthesis sizes $(\leq 25 \mathrm{~mm})$ did.
\end{abstract}

Conclusion: In patients aged 60 and younger, SAVR provides reliable long-term results especially for larger aortic valves. Keywords: Aortic valve, Aortic valve disease, Aortic valve replacement, Stentless aortic valve replacement, Valve replacement

\section{Background}

Stentless aortic valve replacement has become a common surgical treatment of aortic valve disease. These prostheses are designed to allow physiological flow patterns by avoiding an obstructive stent [1]. Various studies revealed controversial results comparing stented and stentless prostheses. However, improved hemodynamics and a larger orifice area could be shown in a recent meta-analysis [2]. In a prospective randomized trial, SAVR showed a midterm survival advantage compared to stented aortic valve replacement (AVR) [3].

Implantation of bioprosthetic aortic valves is still controversial in younger patients. The American Heart Association and the American College of Cardiology recommend bioprosthetic aortic valves in patients above

\footnotetext{
* Correspondence: torsten.christ@charite.de

Department of Cardiovascular Surgery, Charité-Universitätsmedizin Berlin, Charitéplatz 1, 10117 Berlin, Germany
}

the age of 60 years, after lowering the age recommendation down from 65 years in 2010 [4]. Due to their advanced hemodynamics, SAVR might have a better longevity and therefore may be used also in younger patients. The aim of our single-centre retrospective study was to assess the first very long-term results of SAVRs in patients $\leq 60$ years.

\section{Patients and methods}

From 1993 to 2001, 839 patients underwent SAVR. After excluding patients with endocarditis, dissection of the ascending aorta and over the age of 60 years, 188 patients for this study were identified. Either the patient's explicit desire for bioprosthetic AVR or a contraindication to oral anticoagulation caused a decision for SAVR.

Mean age of patients at surgery was $53.1 \pm 7.1$ years. Baseline preoperative characteristics are presented in Table 1. Different types and sizes of prostheses used are shown in Table 2. Isolated SAVR was performed in 120
() Biomed Central

(c) 2013 Christ et al.; licensee BioMed Central Ltd. This is an Open Access article distributed under the terms of the Creative Commons Attribution License (http://creativecommons.org/licenses/by/2.0), which permits unrestricted use, distribution, and reproduction in any medium, provided the original work is properly cited. 
Table 1 Baseline characteristics

\begin{tabular}{|c|c|c|}
\hline Characteristic & Number & Percent \\
\hline $\begin{array}{l}\text { Number of patients } \\
\text { Mean age }\end{array}$ & $\begin{array}{c}188 \\
53.1 \text { years }\end{array}$ & \\
\hline Mean standard error & 7.1 years & \\
\hline Range & $24-60$ & \\
\hline \multicolumn{3}{|l|}{ Sex } \\
\hline Male & 149 & $79.3 \%$ \\
\hline Female & 39 & $20.7 \%$ \\
\hline \multicolumn{3}{|l|}{ Age } \\
\hline$>50$ years & 145 & $77.1 \%$ \\
\hline$\leq 50$ years & 43 & $22.8 \%$ \\
\hline \multicolumn{3}{|l|}{ Left ventricular function } \\
\hline Normal & 109 & $58 \%$ \\
\hline Moderately impaired & 58 & $30.8 \%$ \\
\hline Profoundly impaired & 21 & $11.2 \%$ \\
\hline \multicolumn{3}{|l|}{ Aortic valve lesion } \\
\hline Stenosis & 62 & $33.0 \%$ \\
\hline Insufficiency & 69 & $36.7 \%$ \\
\hline Mixed lesion & 57 & $30.3 \%$ \\
\hline \multicolumn{3}{|l|}{ Timing of operation } \\
\hline Elective & 185 & $98.4 \%$ \\
\hline Urgent/ emergency & 3 & $1.6 \%$ \\
\hline Ascending aortic aneurysm & 21 & $11.2 \%$ \\
\hline Coronary artery disease & 18 & $9.6 \%$ \\
\hline
\end{tabular}

patients. Associated procedures were performed in 68 patients $(36.2 \%)$ and are presented together with operative data in Table 2.

Follow-up data were acquired through telephone interviews. Follow-up was $90.4 \%$ complete at a mean of $8.8 \pm 4.7$ years. 21 patients were lost to follow-up. Total follow-up was 1657.5 patient-years with a maximum of 17.0 years. Data collection and statistical analyses were done according to the current guidelines for reporting mortality and morbidity after cardiac valve interventions [5]. The study was approved by the local Ethics Committee (Ethikkommission der medizinischen Fakultät der Charité - Universitätsmedizin Berlin).

\section{Statistical analysis}

All data were analyzed with PASW Statistics version 18.0.0 (SPSS Inc., Chicago, Illinois). Descriptive statistics are reported as the mean \pm standard deviation for continuous variables and as frequencies and percentages for categorical variables, unless otherwise noted. Survival and time-to-event analyses were performed using Kaplan-Meier actuarial methods. Age-stratified curve comparisons were performed using the log-rank test. All $\mathrm{p}$ values were two-sided. In addition, proportional-
Table 2 Operative data

\begin{tabular}{|c|c|c|}
\hline Procedure & Number & Percent \\
\hline Isolated SAVR & 128 & $68.1 \%$ \\
\hline SAVR + other & 60 & $31.9 \%$ \\
\hline AscAo & 21 & $11.2 \%$ \\
\hline MVR & 16 & $8.5 \%$ \\
\hline CABG & 13 & $6.9 \%$ \\
\hline CABG + other & 5 & $2.6 \%$ \\
\hline Myectomie & 3 & $1.6 \%$ \\
\hline Closure of VSD & 1 & $0.5 \%$ \\
\hline Passive Cardiomyoplasty* & 1 & $0.5 \%$ \\
\hline \multicolumn{3}{|l|}{ Surgical approach } \\
\hline Median sternotomy & 182 & $96.8 \%$ \\
\hline Upper ministernotomy & 6 & $3.2 \%$ \\
\hline \multicolumn{3}{|l|}{ Implanted valves } \\
\hline Edwards Prima-Plus ${ }^{\circledR}$ & 120 & $63.8 \%$ \\
\hline SJM Toronto-SPV ${ }^{\circledR}$ & 50 & $26.6 \%$ \\
\hline Medtronik FreeStyle ${ }^{\circledR}$ & 10 & $5.3 \%$ \\
\hline Vascutec Elan ${ }^{\circledR}$ & 7 & $3.7 \%$ \\
\hline Shelhigh-stentless ${ }^{\circledR}$ & 1 & $0.5 \%$ \\
\hline \multicolumn{3}{|l|}{ Implanted valve sizes } \\
\hline $23 \mathrm{~mm}$ & 3 & $1.6 \%$ \\
\hline $25 \mathrm{~mm}$ & 35 & $18.6 \%$ \\
\hline $27 \mathrm{~mm}$ & 79 & $42.0 \%$ \\
\hline $29 \mathrm{~mm}$ & 71 & $37.8 \%$ \\
\hline
\end{tabular}

AscAo = Replacement of ascending aorta; VSD = ventrical septal defect; $C A B G=$ coronary artery bypass grafting; $M V R=$ mitral valve repair/ replacement; ${ }^{*}=$ ACORN $^{\circledR}$ Cardiac Support Device.

hazard models were used to investigate the following variables as risk factors for survival and freedom from reoperation: gender, age, left ventricular ejection fraction, aortic valve lesion, associated procedures, SAVRdiameter. Left ventricular ejection fraction was assessed by semi-quantitative definitions (normal, moderately impaired, profoundly impaired) due to bias because of the long period of follow-up (involving various physicians and different cardiovascular ultrasound systems). Statistical significance was set at a $\mathrm{p}$ value of less than 0.05 . Preoperative only very few patients showed impaired renal function, diabetes, and essential hypertension (probably due to the low age of the patients) and consequently these characteristics were not entered as covariates in the analysis.

Age- and gender-matched survival estimates from the general German population were obtained from the $\mathrm{Hu}$ man Lifetable Database [6]. Age- and gender-specific conditional probabilities of surviving a 1-year age interval were used to create an age- and gender-matched patient sample. The survival line depicted in the figure comparing the general population with our study cohort 
represents these averaged conditional probabilities of survival.

\section{Results}

\section{Hospital mortality}

Overall hospital mortality was 3.2\% $(n=6)$. Causes for hospital mortality were left ventricular failure $(n=3)$, right ventricular failure $(\mathrm{n}=1)$, electromechanical dissociation $(n=1)$ and multi organ failure $(n=1)$. For isolated SAVR hospital mortality was $2.5 \%(\mathrm{n}=3)$.

\section{Patient survival}

Overall actuarial survival at 10 and 15 years were $73.0 \% \pm$ $3.5 \%$ and $55.8 \% \pm 5.4 \%$, respectively. For isolated SAVR actuarial survival at 10 and 15 years were $70.1 \% \pm 4.4 \%$ and $64.1 \% \pm 4.8 \%$. During follow-up 61 patients died. Linearized mortality rate is $3.6 \%$ / year for overall SAVR and 3.4\%/year for isolated SAVR. Clinical follow-up of the patients with the originally implanted valve still in place showed only 1 patient in NYHA stadium III and no patient in NYHA stadium IV.

Univariate statistical analyses revealed no significant survival difference between isolated SAVR and combined procedures. Neither patients aged $\geq 50$ years and patients aged $<50$ years, nor patients with isolated insufficiency as indication for operation and those with a stenotic valve lesion showed a significant difference in comparison. Additionally also the different models of SAVR did not influence survival.

Various other factors had a significant impact on survival in univariate statistical analysis. Impaired left ventricular function (left ventricular ejection fraction $\leq 50 \%$ ) significantly lowered survival. Patients with impaired left ventricular function showed an actuarial survival-rate at 10 and 15 years of $61.2 \% \pm 5.7 \% / 40.6 \% \pm 8.1 \%$ (Figure 1), respectively. Besides this, patients with larger prosthesis sizes $(\geq 27 \mathrm{~mm}$ ) compared with small prosthesis sizes $(\leq 25 \mathrm{~mm})$ showed a significant survival benefit (Figure 1).

The multivariate proportional-hazard model supports left ventricular function and prosthesis size to be independent risk factors. Additional independent risk factors were age and isolated insufficiency of the aortic valve. (Table 3).

\section{Freedom from reoperation}

Reoperation was performed in 42 patients (22.3\%). Causes were structural valve deterioration $(83.3 \%)$ and endocarditis (16.7\%). Structural valve deterioration caused in most cases (85.7\%) insufficiency and in 14.3\% stenosis.

Overall freedom from reoperation at 10 and 14 years was $81.0 \% \pm 3.4 \%$ and $58.0 \% \pm 7.5 \%$, respectively. For isolated SAVR freedom from reoperation at 10 and 14 years was $83.1 \% \pm 4.0 \%$ and $52.9 \% \pm 9.0 \%$, respectively. Linearized reoperation rate is $2.8 \%$ year.

No significant statistical difference was found between isolated SAVR and combined procedures. Additionally also the different models of SAVR did not significantly influence freedom from reoperation.

Noteworthy, in univariate statistical analysis only small prosthesis size $(\leq 25 \mathrm{~mm})$ significantly lowered freedom
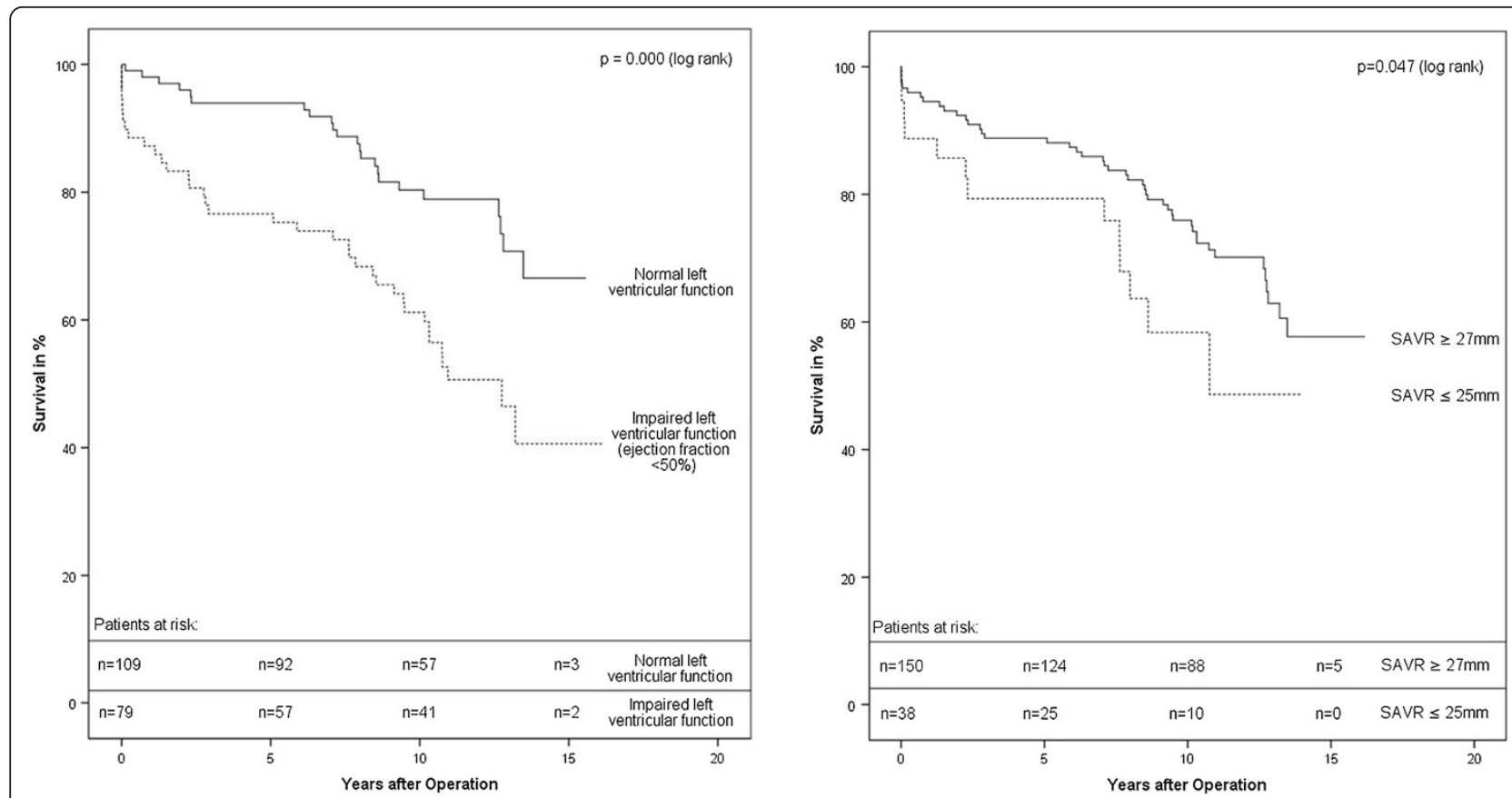

Figure 1 Survival after SAVR (Impact of left ventricular function and size of SAVR). 
Table 3 Risk factors for mortality and reoperation

\begin{tabular}{|c|c|c|c|c|c|c|}
\hline \multirow[b]{2}{*}{ Characteristic } & \multicolumn{3}{|c|}{ Survival } & \multirow{2}{*}{$\frac{\text { Freedom }}{\text { HR }}$} & \multirow{2}{*}{$\begin{array}{c}\text { from } \\
\text { CI }\end{array}$} & \multirow{2}{*}{$\begin{array}{l}\text { Reoperation } \\
\text { Significance }\end{array}$} \\
\hline & HR & CI & Significance & & & \\
\hline Age $(\leq 50)$ & 2.55 & $1.13-5.75$ & 0.02 & 0.98 & $0.45-2.11$ & 0.96 \\
\hline Gender & 1.21 & $0.57-2.64$ & 0.61 & 1.95 & $0.84-4.53$ & 0.12 \\
\hline Aortic valve lesion (stenosis vs. insufficiency) & 0.55 & $0.31-0.95$ & 0.03 & 0.74 & $0.35-1.57$ & 0.44 \\
\hline Left ventricular function (normal vs. impaired) & 0.39 & $0.22-0.68$ & 0.01 & 1.08 & $0.55-2.15$ & 0.05 \\
\hline Associated procedures & 0.94 & $0.52-1.70$ & 0.83 & 0.54 & $0.23-1.25$ & 0.15 \\
\hline SAVR Diameter ( $\leq 25$ mm vs. >25 mm) & 2.15 & $1.13-4.09$ & 0.02 & 3.53 & $1.57-7.92$ & 0.02 \\
\hline
\end{tabular}

$\mathrm{Cl}=$ Confidence Interval, $\mathrm{HR}=$ Hazard ratio.

from reoperation, whereas age ( $\leq 50$ years), aortic valve lesion and combined procedures had no significant influence (Figure 2).

The multivariate proportional-hazard model also revealed only prosthesis size as an independent risk factor (Table 3).

\section{Discussion}

Nonrandomized and randomized clinical trials show evidence that SAVR provides better hemodynamic performance than stented AVR [1,2,7]. This advantage could reduce operative mortality, particularly in those with impaired left ventricular function. Late mortality could be decreased by better left ventricular wall mass regression and performance $[2,8]$.

To compare this study to others is challenging. Most other trials deal with cohorts of patients with far older age. Besides this, our cohort showed a high percentage
(42\%) of patients with impaired left ventricular function (Table 1) with the inherent risk of premature death. Isolated insufficiency as cause of AVR is well presented in our cohort. Inferior early and long term survival has been shown for those patients, especially in younger age $[9,10]$.

In 2010, McClure et al. published a late follow up after implantation of Carpentier-Edwards pericardial AVR. Overall actuarial survival at 10 and 15 years for patients less than 65 years of age was $71.5 \%$ and $43.7 \%$ [11]. The study population underwent more combined procedures and had fewer patients with impaired left ventricular function and insufficiency as cause of operation. Assuming the cohort had the same mean age as ours (no mean age was published) we see a more than $10 \%$ better survival rate after SAVR in our cohort.

Valfré et al. published a 25 year follow up of the Hancock II porcine valve. Their patient cohort had less
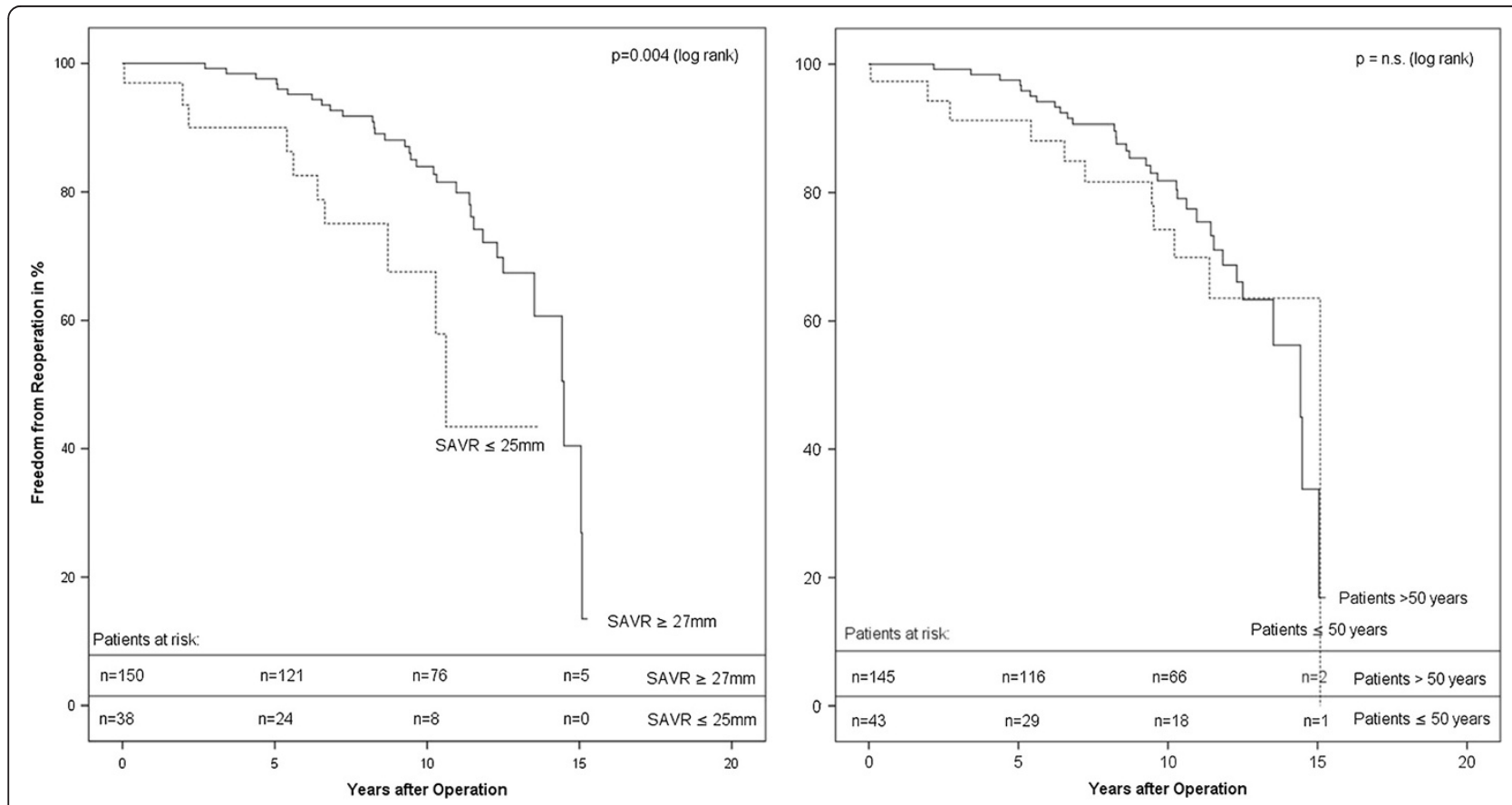

Figure 2 Freedom from Reoperation (Impact of prosthesis-diameter and patients age). 
comorbidities and received less combined procedures. Patients under 60 years showed a 10/15 year survival of $69.4 / 60.0 \%$ [12]. Because no mean age of study population was given, one can only assume comparable long term results.

Ruel et al. described a survival at 10 and 15 years of $82 \%$ and $70 \%$ in patients with a mean age of 47.6 years [13]. They had fewer patients with impaired left ventricular function and less combined procedures. With a 5.5 years older study cohort (in general population this equals a decline in 15 year survival of around $8 \%$ ) our data suggest comparable long term results.

The only randomized prospective trial dealing with patients of almost the same mean age as ours, published by Oxenham et al., compares Bjork-Shiley mechanical valves with porcine AVR. A 10 year survival of $65.7 \%$ for isolated AVR in this cohort is well below our survival rate [14]. One has, however, to consider that those operations were performed in the 1970s.

Several randomized trials showed no significant survival difference between mechanical AVR and bioprosthetic AVR $[14,15]$. However, Ruel et al. showed a (nonsignificant) tendency of better survival towards bioprostheses of around $13 \%$ at a 20 year follow-up and of around $10 \%$ at 25 year follow-up [13]. Above that, they also found a significant difference in freedom from death after 20 years, attributable to ischemic or hemorrhagic stroke, with $97.9 \pm 1.2 \%$ in tissue AVR patients and $83.9 \pm 4.9 \%$ in mechanical AVR patients [13]. Despite lifelong need for anticoagulation treatment and elevated risk of bleeding [14], the risk of thrombembolic complications ranges between $0.7 \%-3.0 \%$, depending on valve type and other risk factors [16].

The above mentioned problems in comparing different study cohorts also compromise the comparison to ageand gender-matched survival estimates from the German general population. To create a comparable cohort, only patients with isolated AVR and normal left ventricular function were analyzed, whereas patients with isolated aortic valve regurgitation as cause of operation were excluded because of the above mentioned impaired survival $[9,10]$. For the above described cohort a survival rate comparable to the general population was seen (Figure 3). One has to take into consideration that reported mortality rates of younger patients after AVR are higher than in the general population, while older patients reach the same survival rate as the general population [17].

Patients with impaired left ventricular function are especially demanding to compare. Survival in this cohort is substantially reduced. At $14.43 \pm 0.54$ years (median time of reoperation observed in this study), survival is at $40.6 \% \pm 8.1 \%$. After SAVR several authors reported a greater improvement of left ventricular function [8] and a resulting survival benefit [18], so that SAVR should be preferred in patients with impaired left ventricular function.

Because small SAVRs $(\leq 25 \mathrm{~mm})$ were associated with inferior survival in our study cohort, patient-prostheses mismatch (PPM) has to be discussed in this context. The concept of PPM was originally introduced by Rahimtoola [19] and describes an effective prosthetic valve area, which is smaller than that of a normal valve, usually defined as effective valve orifice area indexed per body surface (EOAI) smaller than $0.85 \mathrm{~cm}^{2} / \mathrm{m}^{2}$. PPM is not to be expected in larger valve sizes. But smaller valve sizes, especially stented bioprostheses smaller than $25 \mathrm{~mm}$, can be associated with PPM. SAVRs usually fit much more into patients native aortic root compared with stented bioprostheses and offer larger orifice areas due to their stentless construction. Therefore, PPM should not occur in stentless bioprostheses and in a variety of studies EOAI identified no mismatch [20]. Similarly, no case of PPM could be identified in our cohort. Nonetheless, small sizes of SAVRs were related to lower survival. Potentially, there are other factors involved, e.g. the higher reoperation rate in patients with small SAVR could lower patients survival or there could be a direct impact of the lower valve orifice area on survival. But for such conclusion our study population (only $20.2 \%$ of the patients received SAVRs $\leq 25 \mathrm{~mm}$ ) is not large enough and further studies are necessary.

Bioprosthetic AVR showed a time-dependent, decreased longevity, caused by structural valve deterioration [3]. This finally results in a rising need of reoperation. In 2006 the American Heart Association and the American College of Cardiology recommended the use of bioprosthetic aortic valve replacements in patients above the age of 65 years (depending on various other risk factors) [21]. An update in 2010 lowered the age to 60 years [4]. Banbury et al. showed that smaller sizes of bioprostheses have a tendency to lower durability [22]. Due to larger orifice area and less stress on the cusps of SAVR, their durability has been expected to be better than stented AVR. Study results comparing SAVR and stented AVR are controversial in terms of durability. Undoubtedly, the durability of the prostheses decreases along with decreasing age of patients [3]. Thus, the special dependence on the mean age of the study cohort complicates the comparison of studies. Besides this, most studies dealing with stented AVR only describe freedom from reoperation due to structural valve deterioration. In case of SAVR, with the importance of the surgical implantation itself for the function of the valve, overall freedom from reoperation is much more relevant in this study.

Welke et al. published a study on the CarpentierEdwards pericardial AVR, where 58\% freedom from explantation after 10 years was given for patients of 21 to 


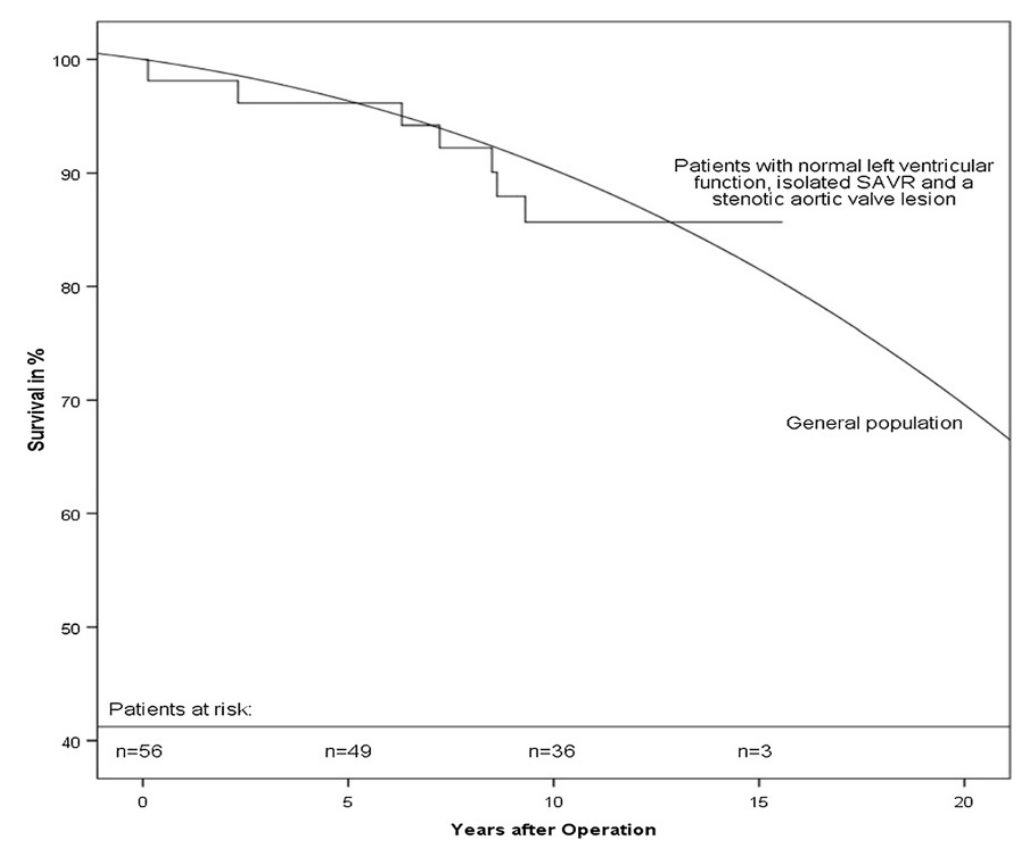

Figure 3 Survival after SAVR compared to general population.

49 years of age, and of $68 \%$ for patients of 50 to 64 years of age [17]. For the same prostheses, age-stratified freedom from reoperation due to structural valve deterioration after 14 years in patients $\leq 65$ years of age was around 35\% [11]. After adding endocarditis and nonstructural valve deterioration this rate may even be worse.

For the Hancock II AVR, Valfré et al. described a freedom from reoperation rate of $62.6 \%$ in a small cohort of patients $\leq 60$ years $(n=50)$ at 15 years [12]. Rizzioli et al. published a 15 year freedom from reoperation rate of $55.8 \%$ for patients $\leq 60$ years [23]. However, in both publications no mean age for the cohort is given.

Ruel et al. described a median time to reoperation of 10.2 years after implantation of stented AVR in a patient cohort with a mean age of 47.6 years [13]. Our patients had a mean age of $53.1 \pm 7.1$ years and the median time to reoperation was $14.43 \pm 0.54$ years.

Mechanical AVR showed lower reoperation rates. The Veterans Affairs Randomized Trial, for example, reports a reoperation-rate after mechanical AVR of $10 \%$ after 15 years [15]. However, this advantage is accompanied by the above mentioned problems [13].

The pulmonary autograft procedure was introduced by Ross in 1967 for young patients with aortic valve disease [24]. The operation is connected with concerns regarding late autograft competence and the consequences of creating pulmonary valve disease. However, long term results are promising $[11,25]$. Chambers et al. published data for the pulmonary autograft procedure. They reported a survival rate of the hospital survivors of $61 \%$, freedom from autograft replacement of $75 \%$, and freedom from replacement of pulmonary position homografts of $80 \% 20$ years after operation [11]. However, one has to keep in mind that the mean age in this cohort was 32 years and the procedures were done between 1967 and 1984.

In recent years a rapid progression of percutaneous AVR can be seen. In Germany, $23.9 \%$ of isolated AVR was performed catheter-based in 2010 [26]. If long-term results are promising and this development persists we can assume that various reoperations can be performed catheterbased. This, however, is only possible after biological AVR.

\section{Limitations}

The retrospective nature of this study design can lead to an underestimation of complication rates (endocarditis, thrombembolic events and bleeding etc.). Because it is likely that some events would not be captured, either because of patients' misinterpretation of our questions or recall bias, some data were not surveyed. Also, NYHA functional class is subjective. Underestimation of symptom severity may lead to overestimation of potential clinical benefit in the statistical analysis. That is why these data were not analyzed. The different types of SAVR used in the researched cohort and pooling of the clinical results may have influenced the valve-related outcomes, even though the type of SAVR did not appear to be of statistical relevance.

Despite these limitations one has to consider the fact that a controlled randomized trial in young patients involving stentless, stented and mechanical AVR is ethically very difficult to perform, if not impossible. 


\section{Conclusion}

In respect of the mentioned limitations of the study and the comparison to other publications (to our knowledge no research for larger cohorts of patients $\leq 60$ years with SAVR is published), our data show long-term results in survival which are comparable or even better than stented AVR and mechanical AVR. Freedom from reoperation is at least comparable to stented AVR. Mechanical AVRs show higher freedom from reoperation, but the risk of reoperation has to be weighed against the risk of lifelong anticoagulation treatment and stroke. In respect of the recent and rapid development in the field of catheter-based AVR, one should also be aware that after mechanical AVR, patients are deprived of this therapeutic option. Comparison of SAVR to the pulmonary autograft procedure in terms of survival is limited due to different mean age of study populations. In terms of freedom from reoperation, the pulmonary autograft procedure is superior.

We conclude that SAVR is a good and safe alternative to mechanical prostheses in patients aged $\leq 60$ years and should be considered preferably in patients with impaired left ventricular function.

\section{Abbreviations}

AVR: Aortic valve replacement; SAVR: Stentless aortic valve replacement; PPM: Patient prosthesis mismatch; EOAl: Effective valve orifice area indexed per body surface.

\section{Competing interests}

The authors report no competing interests.

\section{Authors' contributions}

TC and HG designed the study; TC performed the statistical analysis and drafted the manuscript; BC was involved in collecting data and drafting the manuscript; WK and HG helped to draft the manuscript; WK, HG and BC gave critical comments on the results. All authors read and approved the final manuscript.

\section{Acknowledgements}

The authors gratefully thank Mrs. Katrin Krüger, Mrs. Elvira Plumb and Mrs. Doreen Böttner for their assistance in contacting the patients and collecting data.

Received: 7 January 2013 Accepted: 22 March 2013

Published: 8 April 2013

\section{References}

1. Borger MA, Carson SM, Ivanov J, Rao V, Scully HE, Feindel CM, et al: Stentless aortic valves are hemodynamically superior to stented valves during mid-term follow-up: a large retrospective study. Ann Thorac Surg 2005, 80(6):2180-2185.

2. Kunadian B, Vijayalakshmi K, Thornley AR, De Belder MA, Hunter S, Kendall S, et al: Meta-analysis of valve hemodynamics and left ventricular mass regression for stentless versus stented aortic valves. Ann Thorac Surg 2007, 84(1):73-78.

3. Lehmann S, Walther T, Kempfert J, Leontjev S, Rastan A, Falk V, et al: Stentless versus conventional xenograft aortic valve replacement: midterm results of a prospectively randomized trial. Ann Thorac Surg 2007, 84(2):467-472.

4. Rahimtoola $\mathrm{SH}$ : Choice of prosthetic heart valve in adults an update. J Am Coll Cardiol 2010, 55(22):2413-2426.

5. Akins CW, Miller DC, Turina MI, Kouchoukos NT, Blackstone EH, Grunkemeier $\mathrm{GL}$, et al: Guidelines for reporting mortality and morbidity after cardiac valve interventions. J Thorac Cardiovasc Surg 2008, 135(4):732-738.
6. Statistisches Bundesamt Wiesbaden (Ed): Bevölkerung und Erwerbstätigkeit, Fachserie 1, Reihe 1, Gebiet und Bevölkerung 1993. Stuttgart: Statistisches Bundesamt Wiesbaden, Metzler-Poeschel Verlag; 1995:178-179.

7. Walther T, Falk V, Langebartels G, Krüger M, Bernhardt U, Diegeler A, et al: Prospectively randomized evaluation of stentless versus conventional biological aortic valves: impact on early regression of left ventricular hypertrophy. Circulation 1999, 100(19 Suppl):I16-II10.

8. Ali A, Halstead JC, Cafferty F, Sharples L, Rose F, Coulden R, et al: Are stentless valves superior to modern stented valves? A prospective randomized trial. Circulation 2006, 114(1 Suppl):1535-1540.

9. Li HH, Hahn J, Urbanski P, Torka M, Grunkemeier GL, Hacker RW: Intermediate-term results with 1,019 carbomedics aortic valves. Ann Thorac Surg 2001, 71(4):1181-1187. discussion 1187-1188.

10. Butchart EG, Li HH, Payne N, Buchan K, Grunkemeier GL: Twenty years' experience with the Medtronic Hall valve. J Thorac Cardiovasc Surg 2001, 121(6):1090-1100.

11. Chambers JC, Somerville J, Stone S, Ross DN: Pulmonary autograft procedure for aortic valve disease: long-term results of the pioneer series. Circulation 1997, 96(7):2206-2214.

12. Valfre $C$, lus $P$, Minniti $G$, Salvador L, Bottio T, Cesari F, et al: The fate of Hancock II porcine valve recipients 25 years after implant. Eur J Cardiothorac Surg 2010, 38(2):141.

13. Ruel $M$, Chan V, Bédard $P$, Kulik $A$, Ressler L, Lam BK, et al: Very long-term survival implications of heart valve replacement with tissue versus mechanical prostheses in adults <60 years of age. Circulation 2007, 116(11 Suppl):1294-1300.

14. Oxenham H, Bloomfield P, Wheatley DJ, Lee RJ, Cunningham J, Prescott RJ, et al: Twenty year comparison of a Bjork-Shiley mechanical heart valve with porcine bioprostheses. Heart 2003, 89(7):715-721.

15. Hammermeister K, Sethi GK, Henderson WG, Grover FL, Oprian C, Rahimtoola SH: Outcomes 15 years after valve replacement with a mechanical versus a bioprosthetic valve: final report of the Veterans Affairs randomized trial. J Am Coll Cardiol 2000, 36(4):1152.

16. Butchart EG, Gohlke-Bärwolf C, Antunes MJ, Tornos P, De Caterina R, Cormier $B$, et al: Recommendations for the management of patients after heart valve surgery. Eur Heart J 2005, 26(22):2463-2471.

17. Welke KF, Wu Y, Grunkemeier GL, Ahmad A, Starr A: Long-term results after carpentier-edwards pericardial aortic valve implantation, with attention to the impact of Age. Heart Surg Forum 2011, 14(3):E160-E165.

18. Gulbins $H$, Reichenspurner $H$ : Which patients benefit from stentless aortic valve replacement? Ann Thorac Surg 2009, 88(6):2061-2068.

19. Rahimtoola SH: The problem of valve prosthesis-patient mismatch. Circulation 1978, 58(1):20-24.

20. Pepper J, Cheng D, Stanbridge R, Ferdinand FD, Jamieson WRE, Stelzer $P$ et al: Stentless versus stented bioprosthetic aortic valves: a consensus statement of the international society of minimally invasive cardiothoracic surgery (ISMICS) 2008. Innovations (Phila) 2009, 4(2):49-60.

21. Bonow RO, Carabello B, De Leon Jr AC, Edmunds LH Jr, Fedderly BJ, Freed $M D$, et al: $A C C / A H A$ guidelines for the management of patients with valvular heart disease: a report of the American College of Cardiology/ American Heart Association Task Force on Practice Guidelines (Committee on Management of Patients with Valvular Heart Disease). J Am Coll Cardiol 1998, 32(5):1486.

22. Banbury MK, Cosgrove DM III, White JA, Blackstone EH, et al: Age and valve size effect on the long-term durability of the Carpentier-Edwards aortic pericardial bioprosthesis. Ann Thorac Surg 2001, 72(3):753.

23. Rizzoli G, Mirone S, lus P, Polesel E, Bottio T, Salvador L, et al: Fifteen-year results with the Hancock II valve: a multicenter experience. J Thorac Cardiovasc Surg 2006, 132(3):602.

24. Ross DN: Replacement of aortic and mitral valves with a pulmonary autograft. Lancet 1967, 2(7523):956-958.

25. Kouchoukos NT, Masetti P, Nickerson NJ, Castner CF, Shannon WD, DávilaRomán VG: The Ross procedure: long-term clinical and echocardiographic follow-up. Ann Thorac Surg 2004, 78(3):773-781. discussion 773-781.

26. Gummert JF, Funkat AK, Beckmann A, Ernst M, Hekmat K, Beyersdorf F, et al: Cardiac surgery in Germany during 2010: a report on behalf of the German Society for Thoracic and Cardiovascular Surgery. Thorac Cardiovasc Surg 2011, 59(5):259-267.

doi:10.1186/1749-8090-8-68

Cite this article as: Christ et al: Stentless aortic valve replacement in the young patient: long-term results. Journal of Cardiothoracic Surgery 2013 8:68. 